\title{
Social Media and Female Body Image: A Study on the Imposition of Body Characterization in Tobago
}

\author{
Sharon Campbell Phillips ${ }^{1}$, Deb Proshad Halder ${ }^{2, *}$ \\ ${ }^{1}$ Department of Education, University of the People, Pasadena, USA \\ ${ }^{2}$ Department of English, Faculty of Arts \& Humanities, Jashore Government Women's College, Jashore, Bangladesh
}

Email address:

beautifulblushes $a$ yahoo.com (S. C. Phillips), debuopeople $a$ outlook.com (D. P. Halder)

${ }^{*}$ Corresponding author

\section{To cite this article:}

Sharon Campbell Phillips, Deb Proshad Halder. Social Media and Female Body Image: A Study on the Imposition of Body Characterization in Tobago. Advances in Sciences and Humanities. Vol. 5, No. 4, 2019, pp. 105-113. doi: 10.11648/j.ash.20190504.13

Received: August 11,2019; Accepted: August 26, 2019; Published: September 6, 2019

\begin{abstract}
The popularity of social media has grown considerably over the past few years and has taken a foothold in society. This study examined the connection between extensive social media use and the way people view their bodies in relation to what is seen in the images and messages portrayed on social media. Emphasis is placed on social media and whether it has a negative impact on body image and if it leads to body dissatisfaction. A mixed method approach was taken to collect data on females residing in Tobago and how they perceive body image. Survey participation was both voluntary and anonymous. Participants were females above the age of 15 . Additionally, focus groups were conducted among Tobago women ranging between ages 1656 to further supplement the statistical data collected. The study and the data collected examined how social media influenced the way that women view themselves. The data collected and the research took into consideration how the participants were affected by their exposure to the various social media platforms and their messages. While the information gathered shows there is a correlation between social media and negative body image, there is no evidence to prove that social media has a direct impact on one's body image.
\end{abstract}

Keywords: Social Media, Body Image, Female, Perception, Imposition, Tobago

\section{Introduction}

This thesis focuses on how the use of social media impacts the way women view and feel about themselves. The study seeks to determine whether social media causes one to have a negative body image or some level of body dissatisfaction. The social comparison theory was employed to evaluate social media usage in relation to negative body image. Results from the questionnaire was triangulated with the results garnered from the focus groups to form an integrated analysis of the data collected.

For the purposes of this study, social media is defined as web-based services that allows individuals to (a) construct a public or semi-public profile within a bounded system, (b) articulate a list of other users with whom they share a connection, and (c) view and traverse their list of connections and those made by others within the system. The nature and nomenclature of these connections may vary from site to site
[1]. Since its inception, social media has grown considerably and so has the access to the numerous social media networking sites. The Reference [2] projects the ideation that social media is designed to promote the sharing of user-generated content, communication, and participation on a large scale. These social media networking sites allow individuals to create profiles, share information and photos and choose how and when they will interact with others. There is a considerable number of research that shows the effects of traditional media on body image but there is a shortage of research as to relate how social media use can either negatively or positively affect body image [3]. Evidence from studies likely one conducted by Bell [4] shows that traditional media and their portrayal of the "ideal body image" have marked negative effects on viewers. Most of the studies examined indicate that the media portray a distorted image of an attractive person. This distorted reality that is being presented by the media can cause viewers to become dissatisfied with their own likeness [5].

While there may be other factors that influence how people 
shape their perceptions of the ideal body, social media is the ideal platform to offer persons access to a variety of information (photos, videos and personal information). It can thus be assumed that the various elements presented across the social media platforms can be used for body image comparisons. In a study conducted by Kathryn Bell [4] on female body image and social media, it was revealed that "46 percent of respondents felt pressure to alter images of themselves on social media, particularly their profile picture and 41 percent actually ended up altering them in some way". Bell in her study also referenced a fitness blogger named Casey Ho, who photo - shopped an image of herself based on the comments left on her profile. The comments were negative and spoke to what she needed to improve to attain the "ideal" body. Ho posted the altered photo on her Instagram page with the claim that she had finally obtained her perfect body but still received comments on this improved image, claiming that she was still not perfect according to society's standards of beauty. This story highlights how obsessed society is to pursue the persons achieving what seems to be an unreachable standard of beauty. The lingering question is whether there is such a thing as a perfect body.

\section{Theoretical Discussion}

A study conducted by Pascal Jurgens [6] defines social media as "a subset of mass media that has experienced an increase in use as the Internet has grown in popularity and commonality". This aforementioned statement rings true for the West Indies and in particular Trinidad and Tobago. The terms social media and social networking are both used interchangeably to represent the many online communities that exist in today's society [6]. Del Fresno Garcia et al (p. 24) [7] elaborated saying, "social media are online technology platforms focusing on synchronous and asynchronous human interactions with a local and global reach unprecedented to human history." These types of platforms allows for communication to take place without being face-to-face with the people you are interacting with. The way in which social media allows us to communicate and connect is not something that was expected by society and the growth in its popularity has increased the interest of researchers in studying its effects especially as it relates to body image [8].

Both the social media and the internet have become fundamental parts of everyday living and can now be accessed in on a larger plain than before [6]. It was suggested by Bell \& Dittmar (p. 478) [9] that, "the popularity and availability of more interactive media is increasing." The Internet can be accessed at any time from almost anywhere and with anyone [8], making the access of social media site more convenient. Bell, Diitmar and Klein's statements show that the world is not as big as it used to be and lend support to the view that the world is now a global village. The number of social media outlets that are available to users have continued to grow, these include but are not limited to, Facebook, Instagram, Twitter, Snapchat and YouTube. Del Fresno spoke of the analysis of the interactions of users who have unlimited access to social media. He referred to this as info sociability. Del Fresno et al said that this has led to two phenomena, "on the one hand, the rise of mass auto-communication, and on the other, that every individual has the potential to become a source of micro-media at the same time being the media and part of the message." (Del Fresno et al. 2016). Social media has become an outlet used by other mass media channels to further influence users. The influence that social media has over its users has grown considerably over the years; this is particularly so if the message is divulged by someone who is a celebrity or deemed a public figure. According to Del Fresno Garcia et al. (2016), these figureheads are what we call opinion leaders. Celebrities and public figures alike are "portrayed as having significant influence over others as they selected, modified, and transmitted information/messages of their choosing to the wider public- in essence controlling both the means and the message" (del Fresno Garcia et al. 2016, p. 25). The messages carried throughout the media can affect persons positively or negatively. There are many instances where the messages that are communicated are received negativity as it relates to body image and body dissatisfaction (Bell 2016). A growing trend amongst these social media influencers is showcasing their lifestyles which include their diet and exercise routines, which can give the impression that in order to look like one's favorite celebrity one must do the same things that are being shown.

Ridolfi (2011) defines body image as, "a multidimensional concept that encompasses perceptual, cognitive-affective, and behavioral domains." In other words it is the way that we view ourselves and our own bodies and this may be sometimes in relation to another person. Body image has been discussed by a great number of authors in literature and it, when mentioned, proclaims the reference to negative body image. Bell \& Dittmar [9] defined negative body image as, "the psychologically salient discrepancy between a person's perceived body and their ideal body, which manifests itself as the experience of negative thoughts and esteem about one's body and appearance." Negative body image is also associated with body dissatisfaction. According to Ridolfi et al. (p. 491) [10] body dissatisfaction is, "the cognitive-affective domain of body image, refers to negative and dysfunctional cognitions and emotions about one's appearance." Ridolfi's definition of body dissatisfaction is preferred as it drives home the point of having a negative body image which can transcend into dissatisfaction of one's body I also concur with him when he says that negative body image has become more common on an international level as western media has globalized [10]

Klein (p. 27) [8] wrote, "The strong emphasis placed on social networking and photo sharing can only build on the already existent phenomenon of social psychology, sociology, and media effects theories that help explain body dissatisfaction." The media has always shown what society should believe is the perfect female body. Billboards, magazine ads and movies flaunt an image of the woman who is slim and fit and social media through its connection to the mass media outlets have reinforced this message Women are the ones who usually fall prey to these types of messages as 
the messages are constructed for them. They are taught to believe that their aspirations should be to look like model. The reference [11] says these ideals are "impossible for many people to realistically and healthily achieve." The media usually presents models, celebrities and actresses as the ones having that ideal body that persons should emulate. A study conducted by Pritchard \& Cramblitt [11] claims that a great percentage of the female models are on average 15 percent below the weight of an average female and 95 percent of models are thinner than the average woman. While this study was not completed in Trinidad and Tobago, the findings can be linked to what happens here because we are also being exposed to these models and celebrity figures. Prior research conducted in Trinidad and Tobago concluded that "females experience higher levels of eating disordered behavior than males and that there is a strong link to self-esteem" [12]. The advertisements and the body types that are portrayed persuade women into believing that they should become thinner and weigh less. This can lead to unhealthy practices. Ferguson et al. [13] say, "Increased incidence of eating disorders across the early and mid-twentieth century seem to coincide with trends in the media towards emphasizing thinness in women."

The line between what is real and what is not is often blurred on social media and ideas are generated that make women feel the need to look like the images they see in the media [8]. While the researchers concur with the evidence that suggests increased media consumption can cause the perspective of what is real to become blurred, there is another school of thought promulgated by Bryant, Jennings, Mary Beth and Oliver which creates a more rigid approach to this study. They argue that the messages that are sent out by the media do not directly cause one to engage in body dissatisfaction in a direct hypodermic fashion but prolonged exposure combined with other external factors such as the environment can lead to poor body image [14]. Women are made to believe the pathway to success is achieved by aligning the way they look with that of what the media shows to be the ideal look. There is much literature that speaks to the types of uses and gratification specifically as it relates to social media usage. The reference [15] argues that Facebook users tend to seek enjoyment and knowledge about social activities within their networks, while instant messaging is focused more on relationship building and maintenance. Smock et al. [16] suggest that, while only three motivations predict general Facebook use, a relatively higher number of variables can predict motivations for using specific features such as status updates, comments, chat, and groups. Krause, North, and Heritage (2014) [17] examine motives for listening to music on Facebook and identify three gratifications: entertainment, communication, and habitual diversion. It may be viewed in line with preceding reference that all the reviews given above are relevant as they take into consideration the various reasons that persons use social media and while these are limited to Facebook, we believe it can be applied across all platforms.

While social media usage can be linked to the Uses and gratification theory, we have to also consider the media effects theory, which explains how the media influences the attitudes and perceptions of its audiences. Uses and gratifications can also be explained using socio-cognitive terms (SCT). While research on uses and gratification would focus on the gratifications received, socio- cognitive proposes expected outcomes. Similarly where uses and gratifications researchers posit needs, SCT proposes behavioral incentives [18]. If there are positive results from the use of social media site, the expected result would be continued use and thus further exposure. Past experiences are important in what the current expectation of a user will be, but a point to note is that this expectation can be marred by observing the experiences of others and self-efficacy. The expected outcomes are organized around six basic types of incentives for human behavior: novel sensory, social, status, monetary, enjoyable activity, and self-reactive incentives [19] and these are the erotically constructed rather than statistically derived from exploratory factor analysis as in the uses and gratifications tradition. Social media sites are also used for comparison of oneself to what is shown on the various sites. In the reference [5] the theory of social comparison asserts that: "(1) individuals have a drive to evaluate their opinions and abilities; (2) in the absence of objective, nonsocial criteria, individuals engage in social comparison (i.e., they compare their opinions and abilities to those of other individuals); and (3) whenever possible, social comparisons are made with similar others." People tend to compare themselves to the images that they see on social media. They engage in social comparison and this can result in negative body image.

\section{Scope and Methodology}

\subsection{Scope of the Study}

This study focused on females in Tobago above the age of 15 and how they perceive their body image and society's portrayal of body images as it relates to social media. The intent is to examine the effects social media has on female body image. The first stage of this research took a quantitative approach to data collection. A questionnaire comprising of twenty-six (26) questions was generated and distributed to women across Tobago. The intent of the questionnaire was to garner information from women of different academic backgrounds, and to cover as much geographic and demographic ground as possible. This research method was used to establish a relationship between social media and the way females view themselves as well as how they compare themselves to the images and messages on social media.

O'Leary [20] speaks about the strengths of using this research method. His claim is that administering a questionnaire allows the researcher to gather data specific to their own research and offers insights that might otherwise be unavailable. In listing the additional benefits of questionnaires, O'Leary [20] suggests that they can: (a) reach a large number of respondent (b) represent an even larger population and (c) generate quantifiable and qualitative data.

The chosen topic and some of the questions asked in the questionnaire were identified as sensitive and by using this 
method there was an allowance for anonymity of the respondents, allowing them to be able to answer the questions more honestly. The use of this method also allowed for the generalization of the results and while a questionnaire may sometimes hinder the process of discovery, in this instance, the data collected was compared to a study conducted by Kathryn Bell [4] on female body image and social media in the United States. The comparison was to garner if the same or similar results was produced despite geographical location. Kathryn however, used only a quantitative approach while this paper would use both a qualitative and a quantitative approach for the research.

\subsection{The Rationale of Applying Mixed Method}

The mixed method approach was applied to this study, as the premise of using such an approach is that by the integration of both a qualitative and a quantitative method there would be a more complete and integrated use of the data collected than if the methods were utilized individually. The statistical data collected from the questionnaire was triangulated with the results from the qualitative research method.

Creswell [21] stated that qualitative research techniques provides a different approach to academic inquiry than approaches utilized in quantitative research. Qualitative findings originate from three main forms of data collection: (a) in-depth open-ended interviews, (b) direct observations, and (c) written documents [22].

Creswell [21] outlined nine characteristics of qualitative research:

(i) The information is garnered at the site or natural setting where the problem or issue under study is experienced by the participants.

(ii) The information is collected by the researcher as the sole instrument. This is done by analysis of documents, observation of behaviors and by interviewing participants.

(iii) The researcher who uses the qualitative method does not depend on one form of data collection but rather utilizes a variety of procedures such as interviews, observations, and document analysis.

(iv) The researcher concentrates on the perceptions that the participants hold about the problem or issue.

(v) The researcher uses the inductive method of data analysis to determine and establish themes.

(vi) The study emerges during the process which means that all phases of the process may change. Modification may take place in the questions asked or the participants who were selected.

(vii) Qualitative research is an inquiry in which the researcher is free to make an interpretation of the information he receives.

(viii) The qualitative researcher develops a big, complex picture of the issue in the study by identifying and reporting the multiple factors of the situation.

(ix) The researcher organizes the study around an identifiable social, political, or historical context of the problem.

Our qualitative method of choice will be focus groups. The focus groups will seek to establish if females residing in Tobago compare themselves to the images that are portrayed on the various social media platforms. To begin the focus group sessions Spice's music video titled "Black Hypocrisy" will be shown. This is intended to spark a discussion about self-love and not conforming to society's beauty ideals. A total of three sessions will be conducted with 7 participants per session.

\subsection{The Limitation of the Study}

In conducting research there is always limitations and risk of error. The distribution of the questionnaires will be convenient as they will be done via Google Forms and sent via email, social media platforms such as Facebook and Instagram, and WhatsApp. This method of distribution is simple, but there will be some limitations. In the testing phase of the questionnaire it was indicated to the researchers who attempted the questionnaire that some of the choices could not be seen and that they were not allowed to submit responses when certain devices were used. Another limitation of the questionnaires is that they could be filled out by someone who does not meet the required criteria for accurate completion. Even though the responses are anonymous, the participants are not obligated to be totally honest when answering the various questions. The questions are phrased as simply as possible to avoid misinterpretation, but this could still occur and possibly lead to responses that would not reflect their true thoughts and opinions. A total of 80 persons were sent the link to participate in the survey and only 50 responded. This sample size is not a large one and having a larger sample could lead to more accurate results as a greater sample size would make generalization easier. Conducting the focus group sessions proved a tedious task. It was difficult getting everyone to meet at the agreed upon time. The researchers of this paper were unable to procure the services of a facilitator for the focus groups so the researchers had to conduct the sessions as per the indication of objectives of the paper. The number of focus groups that the researchers had intended to cover was decreased due to the time that the researchers availed themselves.

\subsection{Stratification of Population and Research Tools}

Overall, there were 50 participants who contributed to the study and responded to the survey. All 50 participants were female residing on the island of Tobago. Their ages ranged from 15 to over 36 years old. The survey took the form of a questionnaire and consisted of 26 questions. The style of the questions varied; some of the questions were multiple choice while others were liker scale. Responses to this questionnaire was both voluntary and anonymous. The survey focused on assessing the knowledge base of the participants. It sought to establish their awareness and ideas relating to social media and body image. Questions were asked about personal social media usage and habits. 
The survey assisted for the assessment based on some of the research questions. These were: 'Do respondents feel pressure from social media to change their body or appearance? How do respondents view their own bodies in relation to what they see on social media? Do respondents have negative body image when exposed to social media images?' etc.

A total of 3 focus groups were conducted, with each session comprising of 7 persons. At the beginning of each session Spice's music video and song titled "Black Hypocrisy" [23] was shown.

\section{Discussion}

\subsection{Quantitative Data Presentation}

The first and foremost requirement for the indicated research was to identify whether the participants are used to browsing social media and if they do so how frequently they are habituated to social media and the findings followed:

\section{Which social media site do you use the most?}
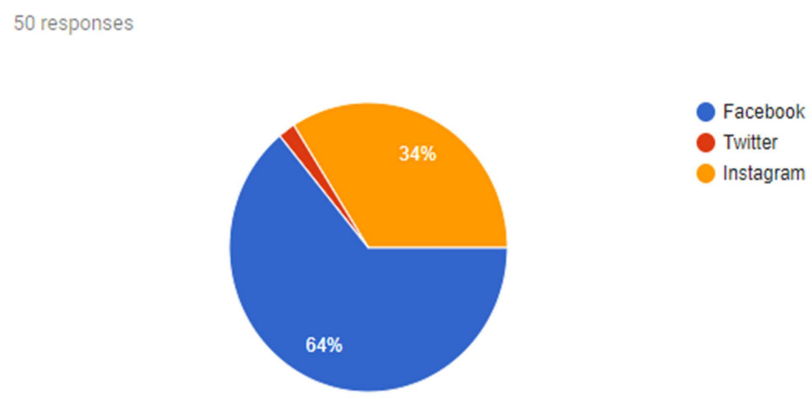

Figure 1. Frequency of Social Media Use.

The Figure 1 shows that 64 percent of the participants use Facebook the most while 34 percent use Instagram and 2 percent use Twitter.

Upon questioning about the reason for their use of social media they responded as 74 percent use social media for personal reasons, 24 percent for Business and 2 percent said they use it for both business and personal reasons. The Figure 2 is the graphical presentation of the prior discussion;

7. What is the primary use of your Facebook page? (Or whichever social media site you use the most)
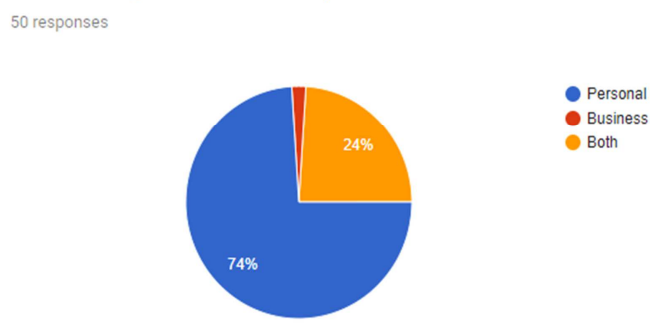

Figure 2. The Utility of Social Media Use.

When asked if their Facebook profile picture was a picture of themselves, 90 percent indicated yes and 10 percent indicated no. The 10 percent said that they used photos of a generic female, blossoming plants or photos of their children.
Figure 3 shows the tendency of self - portrait use for profile picture in social media.

9. If yes to question 8 , did you use a picture of yourself for your Facebook profile? (if answer is yes please skip to question 12)

50 responses

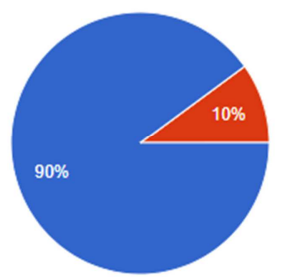

Yes

No

Figure 3. Tendency of Self Picture Use for Profile.

The question no. twelve (12) was intended to inquire for whether the users edited their profile pictures and the findings shows that

\section{Have you ever edited any of your profile pictures? (filters, cropping, Photoshop)}

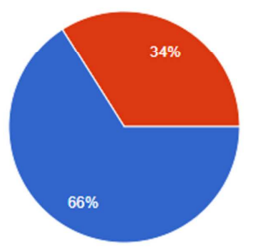

Yes

Figure 4. The Ratio of Image Editing in Profile.

60 percent said they have edited their profile pictures while 34 percent said no. This findings proceed another question directed through question no. thirteen (13) and the findings is shown accordingly through Figure 5:

13. If yes to question 12. Do you feel compelled to edit your profile photo in? (Select one of the following)

50 responses

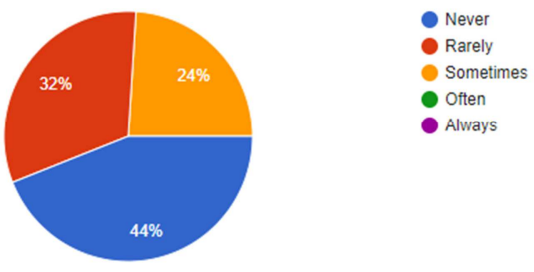

Figure 5. Compulsion of Image Editing.

44 percent claimed to never feel compelled to edit their photo, 32 percent said rarely and 24 percent said that they sometimes feel compelled to edit their photo.

Upon inquiry of their change of ideation regarding the imposition of body image presented in the media for commercial purpose the result was satisfactory enough on the ground that majority percent declined the persuasion of media and the following figure shows accordingly the fact. 
16. I compare myself to others on social media... ( Select one of the following)

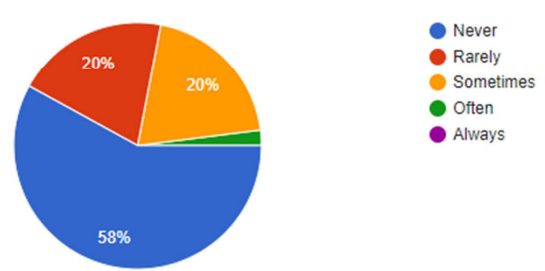

Figure 6. Creation of Imposed Self Image.

56 percent said that they never compare themselves to other on social media, 20 percent said rarely and another 20 percent said sometimes, while 2 percent said that comparison happens often.

But the majority of the respondents are highly exposed to the media pogrom as Figure 7 indicates the information the media addresses with the effect of public reaching maximization.

19. I consider myself to be well informed and aware of media influences (select one of the following)

50 responses
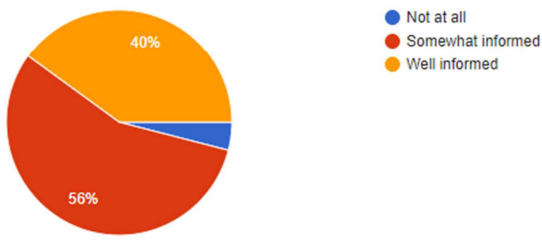

Figure 7. Percentage of Media Influence.

40 percent consider themselves to be well informed of media influences, 56 percent said they are somewhat informed and 4 percent indicated that they are not informed at all.

Again, the social media has maximum coverage to the targeted population of this research paper but it is found that they are little influenced by the media in order to make any edition or addition to their behavior as it projects 80 percent respondents are not influenced by social media for their behavior change, while 20 percent said that media does influence on their behavior.

\section{Does social media influence your behavior?}
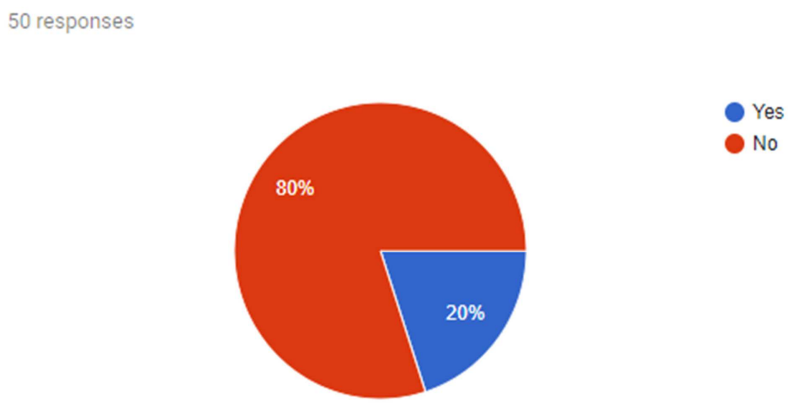

Figure 8. Influence of Media on Behavior.
The self-portrait creates satisfaction to the participants which mean they decline the imposed body image as it claims 54 percent expressed positive feelings while 12 percent expressed negative feelings though

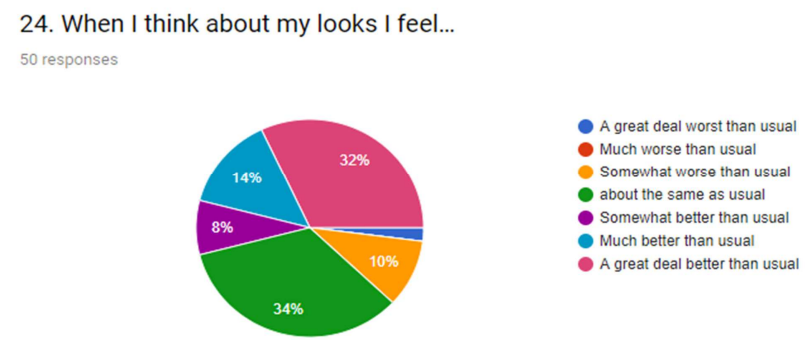

Figure 9. Feelings on Self Appearance.

34 percent felt the same when asked what they think about their looks.

Regarding the measurement of self-gratification, it was the general tone that participants either sometimes, often or always feel satisfied with their physical appearance, body shape, weight and physical attractiveness, while very few were dissatisfied and the scale is high for the 'Sometimes' response regarding the factors of appearance, shape, weight and attractiveness (Figure 10).

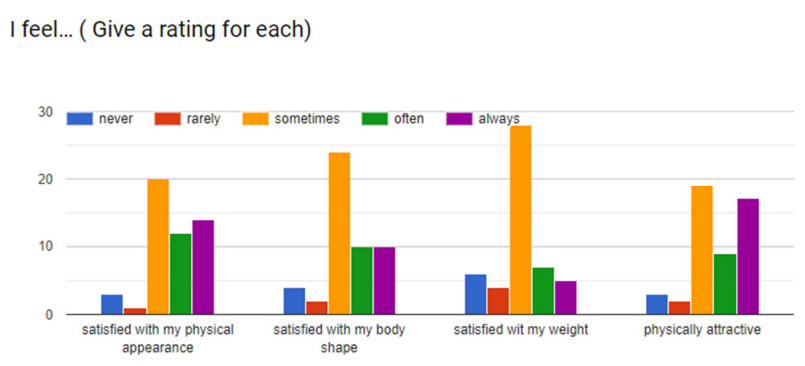

Figure 10. Rating on Self Gratification.

Even, a physical shape of a person cab not be influenced by her image revolved through social media as the Figure 11 presents that fact based on the question no. 26 .

26. Is your self-image influenced by the images that you see on social media?

50 responses

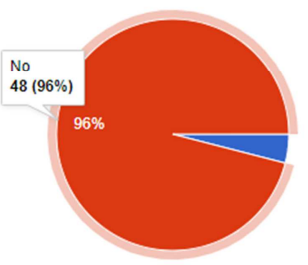

Yes

Figure 11. Social Media Image Influence.

96 percent claimed that images on social media do not influence their self- image while 4 percent said it does.

Again, The majority of the participants felt neutral about the things that show how much their photo are edited, seeing images of slim and beautiful people in the media, seeing 
photos of people who look like them in the media and when they don't get many likes on their photos. A vast majority indicate that they feel good when they get a lot of like on their photos (Figure12).

18. How does the following make you feel? (Give a rating for each)

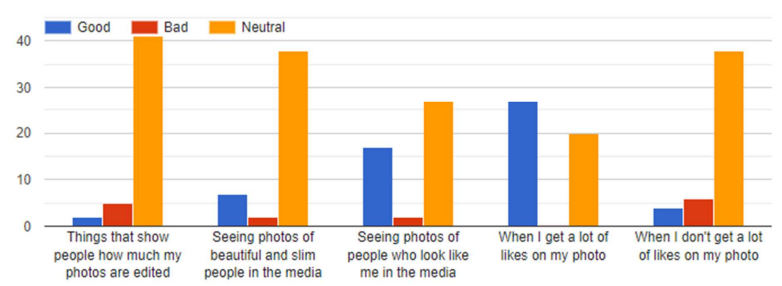

Figure 12. The Feelings on Edited Media Images.

The Findings presented through the Figure 13 provides that at least 40 respondents use social media more than two hours per day and this intensity of online browsing is remarkable in the case of reading newspaper, online shopping, online video watching, leaving behind offline video watching which is alike of the research referred in the [24] that finds 68 students among the one hundred participants are found to have at least a mobile phone (p.64).

22. Approximately how much time do you...( Give a rating for each)
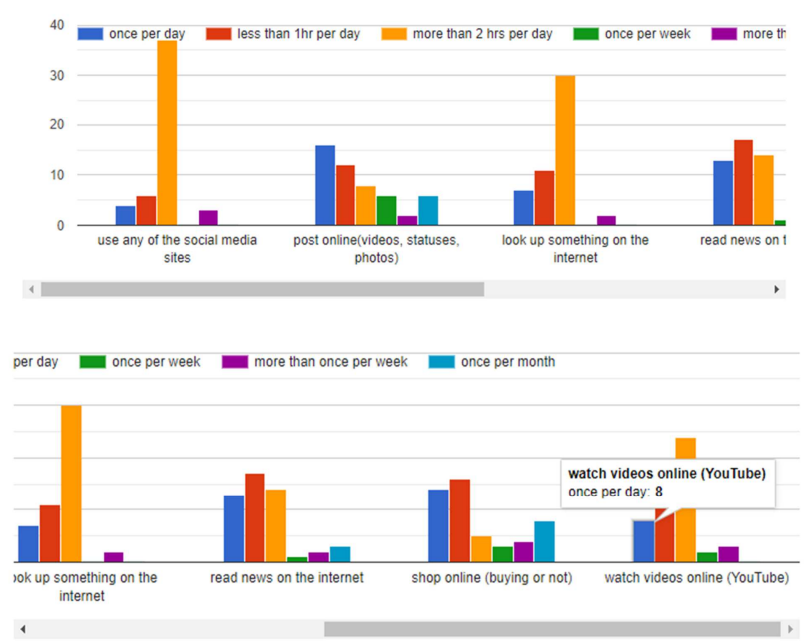

Figure 13. Online Engagement of the Respondents.

The chart shows the various times that participants spent doing activities online.

\subsection{Qualitative Data Presentation}

The music video sparked a lot of discussion. Participants agreed with spice saying that we women need to love ourselves more and not get caught in the hype of looking like what we see on television. The groups agreed that beauty is subjective and there is not a one size fit all definition for what beauty means. One participant shared the following:

When I first saw the video, I cried, I was battling with depression for some time. I think it all really started back in high school. I never really thought that I was an attractive person because I didn't look like the other girls at school or the models I saw on TV. Boys never really looked at me and I would always hear people talking about girls being a "best thing" and I was never referred to as such. I always wanted to have a better body. A bigger bottom or some more breast; something, you know that would make me attractive. I looked at the video and all my built up emotions came running out. Not saying that it gave me self-confidence but it made me realize that society has brainwashed people into thinking that there is one standard definition of beauty.

Question 1: How do you feel when you see image portraying a particular type (social media's definition of beautiful) if you do not look anything like that image?

Most of the respondents said that the images portrayed by social media are just that, images. They didn't feel bad or worse about themselves. One respondent said:

"Those are just pictures and I know most of them don't look like that in real life or if they do, they went and fix their body. I know I am a beautiful woman regardless of what social media has to say."

Question 2: Do you depend on likes and comments via social media to feel good about yourself?

This question was met with a lot of hesitation. Participants were shy at first and then they began talking out. Most said that while positive comments and likes on the photos and post caused them to feel good, they do not rely on these to generally feel good about themselves. Most listed their use of social media and a form of entertainment.

Question 3: Do you compare yourself to the images that you see on social media?

A majority of the participants said that they do not engage in comparison of themselves to images seen on social media. They claimed that those images most times portray something that is not real. A 25 year old participant said:

"Movies and videos will have you out here believing that you aren't worth nothing. But these celebrities have more problems than the average person. I rather look like plain Jane and keep my simple living. Comparing myself to them eh make no sense. God made me like this and he made them like that and God don't make nun ugly. So I don't have time to watch them and want to be them."

\section{Analysis of Findings}

\subsection{Respondents' Feeling of Pressure for Media Imposition}

Of all 50 participants, 100 percent belonged to Facebook or some other type of social media and 90 percent of them used a profile picture of themselves while 10 percent used a generic female photo, photo of their children or flowering plants (Figure 3). 66 percent of participants altered their profile picture (Figure 4), such as photo shop, and 26 percent stated they sometimes felt pressure to alter their profile pictures on social media (Figure 5). While there is a percentage that claims to feel compelled into altering their images on social media, the vast majority of the participants say that they never or rarely feel compelled to change anything. It can therefore 
be said that most people do not feel pressure of changing how they look through social media.

\subsection{Conception on Body and Appearance}

Respondents were asked about their own feelings towards their bodies. 92 percent either were sometimes satisfied or always satisfied with their physical appearance and 34 percent always felt physically attractive (Figure 10). On average, participants were sometimes satisfied with their body shape and sometimes satisfied with their current weight (Figure 10). When asked to think about their looks, 34 percent of respondents felt the same about their looks while 12 percent felt worse. Therefore 54 percent felt positively towards their bodies (Figure 9). Participants in the focus groups were asked of their feelings about their looks in relation to others. A majority felt as if they looked just like the average person and some felt as though they looked worse.

\subsection{Body Exposed to Social Media}

Women in the focus group expressed a desire to be validated. They shared the common theme of seeking validation from online sources. Many compared themselves to images that were seen online and some even expressed that they became depressed when they viewed images online and compared themselves to the images. It was the consensus of the groups that at some point they would have compared themselves to images seen on social media however the comparison did not lead to them having a negative body image, in fact, some commented saying that even though they don't look like women portrayed in the media, they are still happy and satisfied with their images.

\subsection{The Uses and Gratification Theory and the Use of Social Media}

90 percent of the participants revealed that the perception of their bodies is not influenced by social media (Figure 11). Persons in the focus group identified social media as purely a tool for entertainment or connecting with others. As seen in the excerpt in the presentation of finding, question 2 shows how participants feel about the use of social media. The comment further stresses the point of why people use social media. They indicated that social media has no effect on them and that they actively choose to be a part of social media. This would support the Uses and gratification theory which suggests that individuals have power over the media they use and what they use it for. In this instance they explicitly stated that social media was used for entertainment and general communication. No one indicated that there was any form of social comparison taking place.

The research, someway, supports the idea of media influence on individuals but there is not enough evidence to prove or reject it. 74 percent of participants are on social media several times a day to over two hours per day while 100 percent of them belong to Facebook or some other social networking site. 90 percent of them used an image of themselves for their profile picture with 26 percent sometimes feeling pressure to alter the image and 66 percent actually altering it before posting it to their varying social media platforms. Only 12 percent of participants stated that they felt worse about themselves when viewing images of beautiful and thin people in the media. This indicates that 88 percent of the participants either feel neutral or better about themselves after viewing the images. The hypothesis can therefore be rejected since the results of both the survey and the focus groups indicate that females residing in Tobago rarely participate in social comparison, and self-gratification is not the only reason they use social media. After viewing the images, most person felt better about themselves and thus it cannot be said that the exposure of these social media images leads to body dissatisfaction. Participants would have also disproved my preconceived notion that women in Tobago use social media to gratify their need for approval from others.

\section{Conclusion}

Social media has continued to grow in its popularity. It has become a vital outlet for many and a key element of modern communication. A variety of media such as magazine, advertisements and television, radio, etc. are assessable through social media on a continuous basis. Companies that fall under the aforementioned categories now have social media presence, allowing users to be linked directly to website allowing for a constant flow of communication an interaction. The media have often put forward a standard of beauty that is unattainable through videos, images, articles and advertisements. These beauty standards target the female population, pushing upon them and image that society has passed off as ideal. This unattainable beauty standard has oft lead to persons practicing unhealthy habits. Even though a vast majority of these standards are created via applications such as Photoshop and does not really exist, these images are put forward as though they are real. Fortunately, females in Tobago have become more aware of these images and thus do not conform to the messages being sent via the media, including social media. Researchers have seen how exposure to these images can lead to body dissatisfaction but this does not ring true in Tobago. The participants of the survey have indicated that they are mostly informed of the messages that are being put out there and despite those messages, do not compare themselves to the images that are portrayed.

\section{Recommendations}

The results from the study was unexpected, but it does not mean that this is the case for the entire population and there may still be cases where women do engage in social media comparison, which may eventually lead them to develop negative perceptions about their body. It is in this jest that the following recommendations can be made:

\subsection{Tobago House of Assembly}

The Tobago House of Assembly is known for hosting pageants or what we would refer to locally as queen shows. The participants of these show normally fit a particular body type. 
They are usually slender women of a particular height. It is recommended that the Tobago House of Assembly strives to implement a certain level of inclusivity, allowing persons from all spheres to be able to participate in these events. Having persons with varying body types can be a method of improving the message of beauty in all forms to the young women of Tobago.

\subsection{Parents of Teenage Girls}

Parents are advised to pay close attention to the shows and images that their children are exposed to via social media. Since everything is easily accessible and these are their vulnerable years, parents should be keen and take an active role in protecting and educating their charges against negative messages as it relates to body image.

Future research can take into consideration where the pressure is coming from. While the research did find that some participants are pressured into changing how their images look, it did not look at where the pressures were coming from.

\section{References}

[1] Danah m. boyd, Nicole B. Ellison; Social Network Sites: Definition, History, and Scholarship, Journal of Computer-Mediated Communication, Volume 13, Issue 1, 1 October 2007, Pages 210-230, https://doi.org/10.1111/j.1083-6101.2007.00393.x.

[2] Cooper, P. G. Social Media. Salem Press Encyclopedia. 2018. Retrieved from http://search.ebscohost.com/login.aspx?direct=true \& db=ers\& $\mathrm{AN}=89139034 \&$ site $=$ eds-live.

[3] Haferkamp, N., \& Krämer, N. C. Social Comparison 2.0: Examining the Effects of Online Profiles on Social-Networking Sites. Cyber Psychology, Behavior \& Social Networking, 2011, 14 (5), 309-314. https://doi.org/10.1089/cyber.2010.0120.

[4] Bell, Kathryn. Social Media and Female Body Image. In BSU Honors Program Theses and Projects. Item 173, 2016 Availableat: http://vc.bridgew.edu /honorsproj/173.

[5] Festinger, L. A Theory of Social Comparison Processes. Human Relations, 1954, 7 (2), 117-140. doi: 10.1177/001872675400700202.

[6] Jürgens, P. Communities of Communication: Making Sense of the "Social" in Social Media. Journal of Technology in Human Services, $2012 \quad 30 \quad(3 / 4), \quad 186-203$. doi: $10.1080 / 15228835.2012 .746079$.

[7] Fresno García, Miguel Del; Daly, Alan J. y Segado Sánchez-Cabezudo, Sagrario. Identifying the new influencers in the internet era: social media and social network analysis. Revista Española de Investigaciones Sociológicas, 2016, 153: 2340. (http://dx.doi.org/10.5477/cis/reis.153.23).

[8] Klein, Kendyl M. Why don't I look like her? the impact of social media on female body image. CMC Senior Theses. 2013, Paper 720. http://scholarship.claremont.edu/cmc_theses/720.

[9] Bell, B., \& Dittmar, H. Does media type matter? the role of identification in adolescent girls' media consumption and the impact of different thin-ideal media on body image. Sex Roles, 2011, 65 (7/8), 478-490. doi: 10.1007/s11199-011-9964-x.
[10] Ridolfi, D. dridolfi@kent. ed., Myers, T., Crowther, J., \& Ciesla, J. Do Appearance Focused Cognitive Distortions Moderate the Relationship between Social Comparisons to Peers and Media Images and Body Image Disturbance? Sex Roles, 2011, $65 \quad$ (7-8), 491-505. https://doi.org/10.1007/s11199-011-9961-0.

[11] Pritchard, M., \& Cramblitt, B. media influence on drive for thinness and drive for muscularity. Sex Roles, 201471 (5/8), 208-218. doi: 10.1007/s11199-014-0397-1.

[12] Seepersad, R. THE RELATION BETWEEN EATING DISORDERS AND SELF ESTEEM IN ADOLESCENTS IN TRINIDAD. Journal of the Department of Behavioural Sciences, 2012, 2 (1), 102-127. Retrieved December 01, 2018, from https://journals.sta.uwi.edu/ojs/index.php/jbs/article/download /318/289.

[13] Ferguson, C., Muñoz, M., Garza, A., \& Galindo, M. Concurrent and prospective analyses of peer, television and social media influences on body dissatisfaction, eating disorder symptoms and life satisfaction in adolescent girls. Journal Of Youth \& Adolescence, 2014. 43 (1), 1-14. doi: 10.1007/s10964-012-9898-9.

[14] Bryant, Jennings, and Mary Beth. Oliver. Media Effects: Advances in Theory and Research. Third ed., Routledge, 2009.

[15] Asur, S., \& Huberman, B. (2010). Predicting the future with social media. Paper presented at the Web Intelligence and Intelligent Agent Technology (WI-IAT), 2010 IEEE/WIC/ACM International Conference.

[16] Smock, A.D. et al. Facebook as toolkit: A uses and gratification approach to unbundling feature use. Computers in Human Behavior, 27 (6): 2322-2329. November 2011. Doi: 10.1016/j.chb.2011.011.

[17] Krause, A. E., North, A. C., Heritage, B. The uses and gratification of using Facebook music listening applications. Computers in Human Behavior. 39: 71-77. July 2014. Doi: 10.1016/j.chb.2014.07.001.

[18] LaRose, R., \& Eastin, M. S. A social cognitive theory of Internet uses and gratifications: toward a new model of media attendance. Journal of Broadcasting \& Electronic Media, 2004, (3), $358 . \quad$ Retrieved from http://search.ebscohost.com.www.nalis.gov.tt:2048/login.aspx? direct=true \&db=edsglr\&AN=edsgcl.122763711\&site=eds-live.

[19] Bandura, A. From Thought to Action: Mechanisms of Personal Agency. New Zealand Journal of Psychology. 15 (1), June 1986, pp. 1-17. Retrieved from www.psychology.org.nz.

[20] O'Leary, Z. The essential guide to doing your research project (2nd ed.). London: SAGE. 2014.

[21] Creswell, J. Research design: Qualitative, quantitative, and mixed methods approaches (3rd ed.). Thousand Oaks, CA: SAGE, 2009.

[22] Patton, M. Q. Qualitative research and evaluation methods. (3rd ed.). Thousand Oaks, CA: SAGE. 2002.

[23] Spiceofficialent.. Spice - Black Hypocricy [You Tube video]. (2018, October 23) Available from https://vevo.ly/cPOqnp.

[24] Halder, D P. The Extent of Problems and Prospects of Enabling Multimedia Classroom in a City Girls' College in Bangladesh. International Journal of Secondary Education. Vol. 7, No. 3, 2019, pp. 61-68. doi: 10.11648/j.ijsedu.20190703.11. 